ECOLOGICA, Vol. 28, No 104 (2021), 651-657

https://doi.org/10.18485/ecologica.2021.28.104.22

Originalni naučni rad

UDC: 338.43:502.131.1(497.11)

\title{
Analiza uticaja budžetskog finansiranja poljoprivrede na održivi razvoj životne sredine
}

\section{Analysis of the impact of budget financing of agriculture on sustainable environmental development}

\author{
doc. dr Radovan Damnjanović ${ }^{1}$ doc. dr Radan Kostić ${ }^{2 *}$, Miloš Miljković3 ${ }^{3}$ Aleksandar Rajković ${ }^{4}$ \\ ${ }^{1}$ Odeljenje za finansije, Generalštab Vojske Srbije, Beograd, Srbija / \\ Finance Department, General Staff of the Serbian Armed Forces, Belgrade, Serbia \\ ${ }^{2}$ Fond za socijalno osiguranje vojnih osiguranika, Ministarstvo odbrane, Beograd, Srbija / \\ Fund for Military Social Insurance, Ministry of Defense, Belgrade, Serbia \\ ${ }^{3}$ Vojska Srbije, Pančevo, Srbija / Serbian Armed Forces, Pančevo, Serbia \\ ${ }^{4}$ Centar za obuku logistike, Vojska Srbije, Kruševac, Srbija / \\ Logistic Training Centre, Serbian Armed Forces, Kruševac, Serbia \\ ${ }^{*}$ Autor za prepisku / Corresponding author
}

Rad primljen / Received: 09.10.2021, Rad prihvaćen / Accepted: 20.11.2021.

\begin{abstract}
Sažetak: Posmatrajući geografski položaj Republike Srbije, koji predstavlja pogodne uslove za razvoj poljoprivrede a takođe i udeo poljoprivrede u ukupnoj novostvorenoj vrednosti u toku godine, može se zaključiti da je održivo budžetsko finansiranje poljoprivrede jedan od osnovnih ciljeva ekonomskog rasta države. Razmatranje budžeta na adekvatan način daje mogućnost sagledati potrebe uspostavljanja poljoprivrede kao jedne od osnovnih grana koje pozitivno utiču na BDP. Pravilno sagledavanje svih mogućnosti poljoprivrede, mora biti usmereno na očuvanje životne sredine. Iz takvog ugla posmatranja možemo odrediti optimalan način finansiranja poljoprivrede uprkos izazova koji nosi današnje vreme. Pomoću statističkih metoda u radu su istražene uzročno posledične veze između elemenata finansiranja poljoprivrede i njihovog uticaja na ekonomsku moć države.
\end{abstract}

Ključne reči: budžet, poljoprivreda, finansiranje, analiza, ekonomski rast, održivi razvoj, zaštita životne sredine.

\begin{abstract}
Observing the geographical position of the Republic of Serbia, which provides favorable conditions for the development of agriculture, and the share of agriculture in the total newly created value during the year, it can be concluded that sustainable budget financing of agriculture is one of the basic conditions of economic growth. Consideration of the budget in an adequate way provides an opportunity to consider the needs of establishing agriculture as one of the basic branches that positively affect GDP. Proper consideration of all possibilities of agriculture must be aimed at preserving the environment. From such an angle, we can determine the optimal way of financing agriculture, despite the challenges of today. Using statistical methods, the paper investigates the causal links between the elements of agricultural financing and their impact on the economic power of the state.
\end{abstract}

Keywords: budget, agriculture, financing, analysis, economic growth, sustainable development, environment protection.

10rcid.org/0000-0002-4574-5546, e-mail: radovandamnjan@gmail.com

2orcid.org/0000-0002-1642-1278, e-mail: kostic.radan1976@gmail.com

3orcid.org/0000-0001-5848-6320, e-mail: milos.miljkovic.mekis@gmail.com

40rcid.org/0000-0001-6137-3749, e-mail: rajkovic.aleksandar1991@gmail.com 


\section{UVOD / INTRODUCTION}

Privredna delatnost kao što je poljoprivreda od krucijalnog je značaja u političkom, socijalnom i ekonomskom smislu. Uspostavljanje pravilnog i održivog finansiranja poljoprivrede je od velikog značaja za svaku zemlju jer budžetski rashodi zapravo predstavljaju veliku finansijsku podršku potrebama poljoprivrede. Posmatrajući finansiranje u svim realnim sektorima: direktnim zajmovima, emitovanjem hartija od vrednosti na tržištu hartija od vrednosti metodom transfera se dolazi do toga da se na isti način finansira i poljoprivreda (Knežević i dr., 2017). Ovaj rad fokusiran je na finansiranje poljoprivrede iz budžeta Republike Srbije. Istorijski posmatrano finansiranje poljoprivrede je sve do usvajanja Programa rekonstrukcije monetarnog sistema 1994. godine, bilo je u direktnoj zavisnosti od države. Takvo finansiranje se baziralo na primarnoj emisiji $i$ davanju kredita pod povlašćenim uslovima. Država je tada ostvarivala uticaj čak i na bankarski sektor koji je iz sopstvenih izvora emitovao bankarske proizvode - kredite. Svaki oblik finansiranja i u dugom i u kratkom roku bio je pod jurisdikcijom države.

Svaki privredni subjekat i sve finansijske institucije za cilj imaju maksimizaciju profita što se za budžet kao finansijsku instituciju ne može reći. On se posmatra kao zamajac očuvanja i razvoja delatnosti koje su od značaja za društvo i državu. $\mathrm{Na}$ osnovu karakteristika budžeta kao finansijske institucije i poljoprivrede kao privredne grane možemo dovesti u vezu uticaj budžetskog finansiranja na razvoj poljoprivrede.

\section{BUDŽET KAO FINANSIJSKA INSTITUCIJA / BUDGET AS A FINANCIAL INSTITUTION}

Budžet predstavlja osnovu finansiranja javnih rashoda, on je osnovni, a u pojedinim situacijama $i$ jedini instrument prikupljanja javnih prihoda. Budžet je složen instrument koji je povezan sa javnim prihodima i rashodima. Postoji više funkcija budžeta i one su u uskoj vezi sa postavljenim ciljevima države koje se ostvaruju kroz jednogodišnje dejstvo budžeta (Burda \& Viploš, 2012).

$U$ ovom radu, od svih prethodno pomenutih funkcija budžeta, fokus je postavljen na ekonomsku funkciju, kao najznačajniju sa gledišta ovog istraživanja. Ekonomska funkcija budžeta utemeljenje pronalazi u instrumentima koje vlada koristi za postizanje ciljeva preko javnih rashoda i prihoda, $s$ obzirom na to da ima direktan uticaj na preraspodelu domaćeg bruto proizvoda (BDP). Javna potrošnja se posredstvom budžeta uvezuje sa ekonoskom politikom i postavljenim ciljevima koje treba dostići u raspodeli društvenog proizvoda (llić i dr., 2017). U kapitalističkoj privredi gde su uočljivi međusobno suprostavljeni interesi različitih društvenih grupa, državi kao nosiocu ekonomske politike predstavlja ni malo jednostavni zadatak primeniti stabilizacione mere, uprkos konstatacije da je u eri tehničkih i informatičkih dostignuća pristup informacijama u velikoj meri olakšan. Na osnovu toga, principi teorije javnog izbora postali su relevantni za intervencije države u određenim baznim privrednim delatnostima od značaja, kakva je sigurno i poljoprivreda (Ignjatijević i dr., 2020).

\section{POLJOPRIVREDA KAO EKONOMSKA DELATNOST / AGRICULTURE AS AN ECONOMIC ACTIVITY}

Kao privredna delatnost, koja sa značajnim procentom učestvuje u BDP, poljoprivreda, a posebno nakon perioda tranzicije, se može posmatrati kao značajan temelj oporavka države. Bez obzira da li je reč o primarnoj ili multifunkcionalnoj poljoprivredi, u zemljama koje imaju razvijeno tržište, poljoprivreda ima privilegovan položaj u odnosu da ostale privredne delatnosti (Živković \& Veljković, 2020). Takva privilegija se prvenstveno uočava u Evropskoj uniji koja svoju poljoprivrednu politiku zasniva na podsticajnim sredstvima u vidu bespovratnih kredita, ili poljoprivreda SAD koja je pak zasnovana na povoljnim kreditima sa izrazito niskom kamatnom stopom.

Kao važan segment privrede, poljoprivreda je prešla dug put evolucije kako bi danas izgledala savremeno i moderno u velikom broju razvijenih zemalja. Evolucija poljoprivrede, sve do industrijske revolucije je bila dug i izuzetno spor proces, iako je i u tom vremenskom razdoblju bila jedna od osnovnih privrednih delatnosti. Razvoj poljoprivrede neminovno je uslovljen prirodnim i društvenoekonomskim faktorima (Devetaković i dr., 2019.).

U Srbiji prema rezultatima popisa iz 2012. godine ukupno ima 68.242 gazdinstava u kojima je jedini izvor zarade ili drugih primanja isključivo poljoprivredna proizvodnja. Na osnovu prikupljenih podataka možemo videti da je u Srbiji izuzetno zastupljena primarna proizvodnja ili poljoprivreda u užem smislu i da je to ključna delatnost domaćih poljoprivrednih proizvođača. U našoj zemlji $47 \%$ od ukupnog broja gazdinstava koristi samo 2 hektara poljoprivrednog zemljišta što je izuzetno mala iskorišćenost poljoprivrednog zemljišta (Đurić i dr., 2020). Takav način bavljenja poljoprivredom je neodrživ iz razloga nepostojanja konkurentske proizvodnje i nemogućnosti smanjenja troškova poslovanja. Nasuprot pokazateljima u našoj zemlji, u zemljama Evropske unije ta iskorišćenost iznosi 20 hektara te je i konkurentnost na tržištu veća, a troškovi poslovanja se mogu smanjivati jer se kvantitetom može nadomestiti cena (Veličković \& Jovanović, 2021). 
Visok stepen uticaja na poljoprivredu imaju biološke specifičnosti, te je finansiranje iste komplikovanije od drugih privrednih delatnosti. Ti uticaji su uočljiviji pri sezonskoj i organskoj poljoprivrednoj proizvodnji. Treba navesti probleme koje je neophodno rešavati: specijalizacija proizvodnje, iskorišćenost kapaciteta i spor obrt kapitala. Postoji potreba da se u kratkom roku angažuju velika finansijska sredstva. Iz tog razloga proističe niska profitabilnosti poljoprivrede, i neophodnost obezbeđivanja dodatnih izvora finansiranja poljoprivrede (Milosavljević i dr., 2019). Iz svega navedenog sledi zaklučak da rešenje za vraćanje poljoprivrede u život leži u većem izdvajanju iz opšteg budžeta za finansiranje agrarnog budžeta kao i implementacija dodatnih programa kreditiranja od strane razvojnih i poslovnih banaka.

\section{AGROBUDŽET I FINANSIRANJE POLJOPRIVREDE / AGRICULTURAL BUDGET AND FINANCING OF AGRICULTURE}

Agrarna politika je deo nacionalne ekonomske politike, koja usmerena je na razvoj poljoprivrede.

$\mathrm{Da}$ je poljoprivreda usko povezana sa zaštitom životne sredine, a samim tim i zaštitom prirode, govori nam podatak da je 2016. i 2017. godine Ministarstvo poljoprivrede bilo objedinjeno sa sadašnjim Ministarstvom zaštite životne sredine i nosilo je naziv Ministarstvo poljoprivrede i zaštite životne sredine (Zakon o ministarstvima, 2015).

Uslovljenost izdvajanja za poljoprivredu usko je povezana sa izdvajanjima za zaštitu životne sredine. Agrarnu politiku čine elementi kao što su: cilj, sredstva, mere i način delovanja odnosno metode $\mathrm{i}$ takođe najmanje bitni nosioci agrarne politike. Ovi elementi su u sinergiji i deluju jednovremeno na određenom prostoru, a rezultat im je da postignu promene u oblasti poljoprivrede ili aktivnosti koje su u korelaciji sa poljoprivredom (Devetaković i dr., 2019).

Državnom budžetu je 1996. godine pripojen i agrarni budžet i od tada on figurira u okviru državnog. Takav vid konsolidovanog budžeta omogućava državi da preko subvencija poljoprivredi vrši uticaj na proizvodnju. Svake godine na kraju tekuće ili početkom naredne se vrši usvajanje budžeta kroz Zakon o budžetu, koji predlaže Vlada Srbije. $\mathrm{Na}$ osnovu potreba za finansiranjem prioritetnih oblasti poljoprivrede, Ministarstvo poljoprivrede predlaže rashode i izdatke koji se ugrađuju u budžet. Analizom podataka iz Tabele $1 \mathrm{u}$ periodu 2016-2020. godine, zaključuje se da je učešće agrarnog budžeta u ukupnom budžetu Republike Srbije u proseku nešto iznad 4,0\%. Kako bi se poljoprivredni razvoj poboljšao neophodno je da se u narednim godinama povećava učešće agrara u ukupnom budžetu Republike. Takođe, zbog održivog razvoja životne sredine potrebno je povećanje izdvajanja iz ukupnog budžeta i za ovaj deo društvene sfere. Primera radi, Evropska unija oko $20 \%$ izdvaja za ruralni razvoj (Sachs et al., 2019).

Finansiranje poljoprivrede se realizuje iz sredstava budžeta preko agrarnog budžeta i to kreditiranjem. Nadležno ministarstvo 2010. godine otpočelo sistem kreditne podrške kako plasmanom kratkoročnih tako i dugoročnih kredita, u saradnji sa poslovnim bankama. Ovakav vid kreditiranja odlikuju niske kamatne stope, a sve sa ciljem da korisnici istih imaju lakši pristup kreditnom tržištu (Pantić i dr., 2019).

Značajnu ulogu u podsticaju poljoprivrede ima i kreditiranje poslovnih banaka. $U$ tranzicionom periodu krediti poslovnih banaka namenjeni poljoprivredi nisu bili naročito povoljni i pristupačni. Osnovne karakteristike su im bile visoke kamatne stope, troškovi osiguranja su bili ogromni, a grejs period nije postojao. Sve je to proizilazilo iz nesigurnosti ulaganja u poljoprivredu. Stvaranjem veće i bolje konkurencije na tržištu bankarskih proizvoda i participiranjem većeg broja banaka, takav loš trend se promenio i danas su uslovi znatno povoljniji za finansiranje poljoprivrede. Takav razvoj situacije omogućio je niže kamatne stope i plasman kratkoročnih kredita indeksiranih u domaćoj valuti. Jedina nepovoljnost koju bi u narednom periodu trebalo rešiti je kreditiranje poslovnih banaka dugoročnim kreditima indeksiranim u evrima. (Veselinović \& Drobnjaković, 2014). Autori smatraju da bi optimalan vid finansiranja bio ustrojen na način da se poljoprivredi i svim njenim činiocima ponude poljoprivredni krediti bez valutne klauzule koji bi bili prilagođeni sezonskom karakteru poljoprivredne proizvodnje i finansijskoj moći konkretnih činilaca.

$\mathrm{Na}$ osnovu svega navedenog, a po mišljenju autora, trebalo bi razmotriti opciju formiranja poljoprivredne banke čije bi se poslovanje baziralo na modelu poslovih banaka u zemlji (Mihajlović i dr., 2016). To poslovanje bi trebalo biti s mnogim pogodnostima i povlasticima poljoprivrenim subjektima i potencijalnim korisnicima. Finansiranje takve banke bi bilo iz republičkog ili iz agrarnog budžeta, kamatne stope bi bile niske, bez valutne klauzule, i prilagođene sezonskom karakteru poljoprivredne proizvodnje. Grejs period bi bio značajnije produžen.

Za finansiranje poljoprivrede može se koristiti status države Srbije, kao kandidata za članstvo u Evropskoj uniji. Sticanjem prava kandidata Srbija je stekla i mogućnost da konkuriše za korišćenje predpristupnih poljoprivrednih fondova u okviru Evropske unije. Ovakvim načinom finansiranja, Evropska unija teži da na što bolji način pripremi države - 
buduće članice za implementaciju mera zajedničke poljoprivrdene politike u svojoj pravnoj normi, ali i praksi, a sve radi održivog finansiranja i ruralnog razvoja. Ovaj vid finansiranja poljoprivrede u direktnoj je vezi sa budžetom jer ga dodatno rasterećuje. Diskusija se može voditi o tome da li je privilegija $i$ povoljnost evropske poljoprivredne politike dobra za državu. Mogućnost Evropske unije je velika, jer je svojim proizvodima znatno konkurentnija na tržištu upravo zbog subvencija koje daje svojim proizvođačima, pitanje je da li bi i u kojoj meri poljoprivreda Srbije mogla da bude konkurentna razvijenoj evropskoj poljoprivredi.

\section{MATERIJALI I METODE /}

\section{MATHERIALS AND METHODS}

Predmet istraživanja u radu, direktno je uticao na odabir metode istraživanja, tako je u radu korišćena metoda korelacije za koju autori smatraju da je najodgovarajuća u cilju formiranja relevantnih zaključaka. Ovu metodu koristimo za utvrđivanje u kakvom su odnosu stanje i struktura rashoda iz budžeta i indivudualni elementi činioca poljoprivrede u Republici Srbiji. Osnovni i polazni inputi u istraživanju su BDP i budžet. Osim ova dva činioca, u istraživanju su razmatrani i odnosi između budžetskih izdvajanja-rashoda za poljoprivredu. U Tabeli 1 u koloni 3. predstavljen i udeo agrarnog budžeta $u$ ukupnom budžetu datom u koloni 4 Tabele 1 .

Kao ocena u kakvom se stanju nalazi poljoprivreda, koriste se pokazatelji subvencije za poljoprivredu, izvor poljoprivrednih i prehrambenih proizvoda, na osnovu njih se utvrđuje stepen subvencionisanja poljoprivrede $\mathrm{u}$ odnosu na rashode budžeta.

Kao ponder stanja sektora poljoprivrede iskorišćeni su sledeći pokazatelji:

Kako bi se BDP-a strukturno prikazao, primenjen je rashodni model gde je BDP prikazan kao

$$
B D P=C+G+I+X-M
$$

gde je sa $C$ označena lična potrošnja, sa $G$ javna potrošnja, I u navedenoj formuli predstavlja investicije, $X$ - izvoz, a $M-$ u ovom slučaju predstavlja uvoz.

Model korelacije Pearson-ov koeficijent (Dominic et al., 2021) je primenjen prilokom rada sa podacima na sledeći način:

$$
r_{x y}=C_{x y} / S D_{x} * S D_{y},
$$

pri čemu $C_{x y}$ predstavlja kovarijansu, $S D_{x}$ označava standardnu devijaciju $x, a S D_{y}$ pokazuje standardnu devijaciju $y$.

Metod linearnog trenda

$$
\widehat{y}=b_{0}+b_{1} x \text {, }
$$

gde je $\hat{y}$ linearna funkcija, $b_{0}$ prosek, a $b_{1}$ srednja apsolutna vrednost u vremenu $h$, je primenjen radi dolaska do podataka o kretanjima ukupnih rashoda iz budžeta vezanih za finansiranje kulture. Njime će se doći do zaključka na koji način će eventualni rashodi u narednim godinama izgledati kao i izgledi za njihovo uvećanje odnosno smanjenje, a za izračunavanje ocene parametara trenda koristi se metod najmanjeg kvadrata (Mladenović \& Nojković, 2015).

\section{REZULTATI I DISKUSIJA / RESULTS AND DISCUSSION}

Primenom pomenutih metoda na podatke koji su prikupljeni u ovom istraživanju dobijeni su sledeći rezultati:

U radu je izvršena analiza republičkog budžeta, označena kao $(x)$ i dok su sa $(y)$ označene subvencije koje država izdvaja iz budžeta za poljoprivredu. Upotrebom PEARSON-ovog metoda korelacije utvrđeno je da korelacije iznosi $r_{x y}=0.97$ što ukazuje da su ove dve pojave u pozitivnoj korelaciji koja je izrazito jaka.

Ako se sa $(x)$ označe subvencije iz budžeta, a sa (y) proizvodnja poljoprivrednih dobara i usluga po tekućim cenama, primenom napred pomenutog metoda korelacije dobija se vrednost korelacije $r_{x y}=0.62$ što nam ukazuje na pozitivnu korelaciju između ove dve pojave.

Primenom PEARSON-ove metode korelacije ustanovili smo da je vrednost koeficijenta korelacije, između (x) izdvajanje iz budžeta za poljoprivredu i (y) ukupni saldo spoljnotrgovinske poljoprivredne i prehrambene proizvodnje: $r_{x y}=0,25$, što označava pozitivnu, ali ne izrazito jaku korelaciju.

Primenom metoda korelacije i posmatranjem rezultata do kojih se došlo u ovom radu, utvrđeno je da je republički budžet u izrazitoj korelaciji sa subvencijama za poljoprivredu, tako da u u slučaju kada se povećava budžet, doći će do rasta i subvencija za poljoprivredu.

Povezanost ova dva analizirana inputa i njihovim upoređivanjem, deluje pozitivno, jer izdvajanja iz budžeta za subvencije za poljoprivredu paralelno prati i rast republičkog budžeta. Ako bi se dugoročno izvršila analiza došlo bi se do zaključka da svi troškovi finansiranja kroz subvencije za poljoprivredu predstavljju javne rashode. Finansiranja poljoprivrede putem subvencija predstavlja dugoročnu delatnost za koju su potrebna izuzetna finansijska ulaganja. Kada vlast ne bi izdvajala sredstva iz republičkog budžeta za subvencije, to bi bilo povoljno finansijski gledano za budžet Republike Srbije jer ne bi bio opterećen dodatnim rashodima. 
Tabela 1. Ekonomska kretanja u Srbiji od 2016. do 2020. godine (u milionima dinara) Table 1. Economic trends in Serbia from 2016 to 2020 (in millions RSD)

\begin{tabular}{|c|c|c|c|c|c|c|}
\hline Godina & $\begin{array}{c}\text { Budžet } \\
\text { Republike } \\
\text { Srbije }\end{array}$ & $\begin{array}{c}\text { Izdvajanja iz } \\
\text { budžeta za } \\
\text { poljoprivredu }\end{array}$ & $\begin{array}{c}\text { Subvencije iz } \\
\text { budžeta RS za } \\
\text { poljoprivredu }\end{array}$ & $\begin{array}{c}\text { Proizvodnja } \\
\text { poljoprivrednih } \\
\text { dobara i usluga po } \\
\text { tekućim cenama }\end{array}$ & $\begin{array}{c}\text { Ukupni saldo } \\
\text { spoljnotrgovinske } \\
\text { poljoprivredne } \\
\text { razmene }\end{array}$ & $\begin{array}{c}\text { Učešće agrar- } \\
\text { nog budžeta u } \\
\text { ukupnom } \\
\text { budžetu RS (\%) }\end{array}$ \\
\hline 1 & 2 & 3 & 4 & 5 & 6 & 7 \\
\hline 2016 & $997,427.65$ & $40,465,69$ & $27,951.49$ & $589,817.8$ & $166,011.67$ & 4,1 \\
\hline 2017 & $1,092,883.50$ & $43,787.55$ & $31,600.71$ & $543,746.5$ & $155,305.81$ & 4,0 \\
\hline 2018 & $1,178,448.35$ & $44,109.23$ & $34,315.13$ & $589,704.3$ & $144,840.30$ & 3,7 \\
\hline 2019 & $1,292,640.26$ & $54,614.66$ & $43,711.69$ & $605,291.2$ & $152,818,39$ & 4,9 \\
\hline 2020 & $1,314,521.03$ & $52,713.01$ & $41,008.75$ & $667,854.8$ & $181,338.91$ & 4,0 \\
\hline
\end{tabular}

Izvor: www.stat.gov.rs

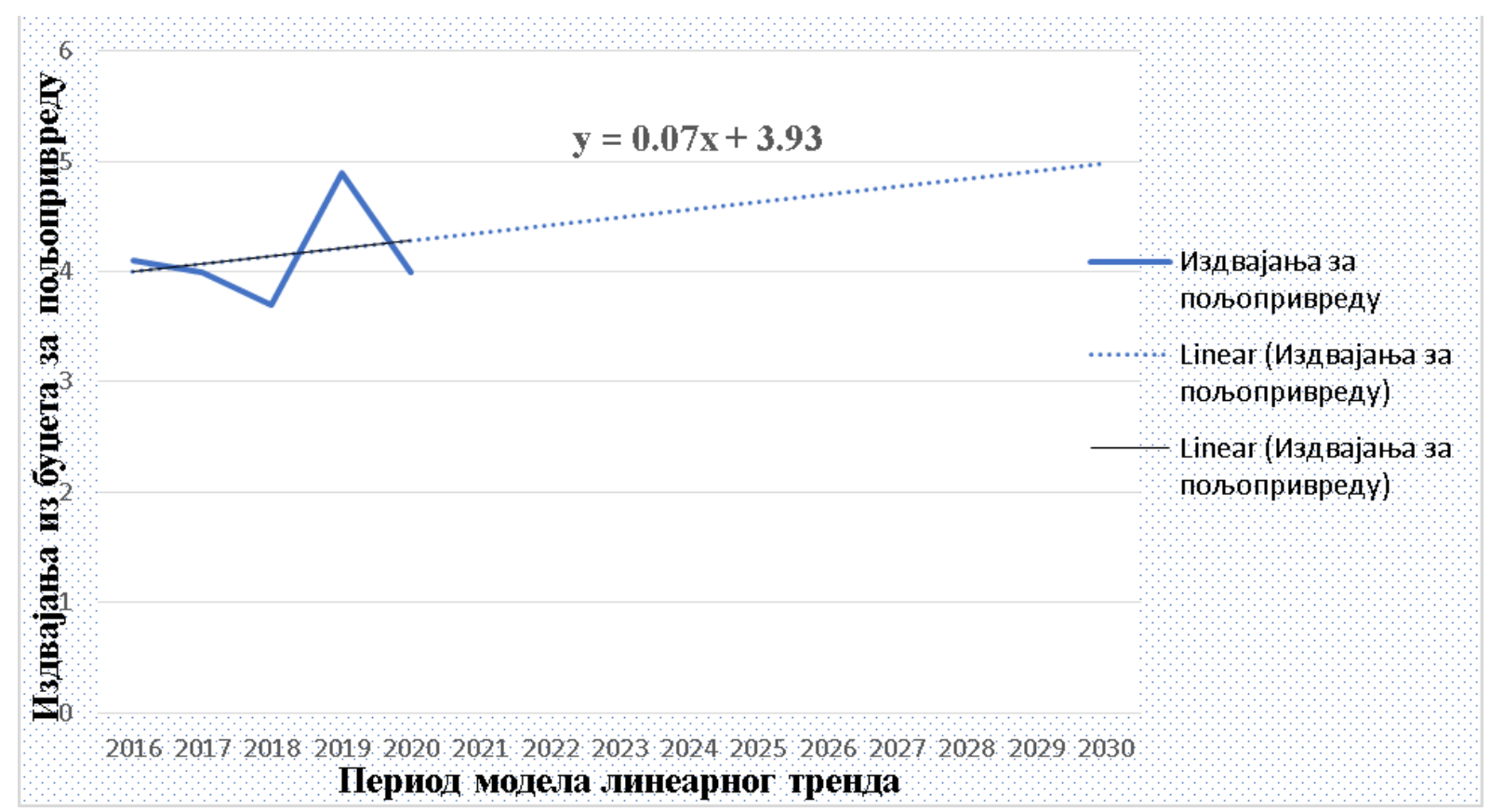

Slika 1. Izdvajanja iz budžeta RS za poljoprivredu i model linearnog trenda

Figure 1. Allocations from the RS budget for agriculture and the linear trend model

lako je korelacija ova dva posmatrana elementa povezana potrebno je dodatno finansirati poljoprivredu kao jednu od primarnih privrednih delatnosti u zemlji, jer kao što je u prethodnom tekstu rečeno, poljoprivreda bi mogla da bude veliki zamajac daljeg razvoja privredne proizvodnje. Analizom je utvrđena i korelacija između subvencija za poljoprivredu i izvoza poljoprivrednih i prehrambenih proizvoda koja je pozitivna. Iz pozitivne korelacije ova dva elementa utvrđuje se da s rastom subvencija za poljoprivredu raste i izvoz poljoprivrednih prehrambenih proizovoda. Ovakva korelacija upućuje i na to da je potrebno izdvajanje iz budžeta za poljoprivredni budžet uvećati jer će se na taj način uvećati poljoprivredna proizvodnja, a samim tim ostvariti i veći prihodi budžeta.
U ovom radu je je takođe posmatrana korelacija između izdvajanja za agrar i ukupnog salda spoljnotrgovinske poljoprivredne i prehrambene proizvodnje. Veza između ova dva elementa je pozitivna, što upućuje da rastom budžeta za poljoprivedu, raste, ne u velikoj meri, i ukupni saldo spoljnotrgovinske poljoprivredne i prehrambene proizvodnje. Korelacija je pozitivna, ali ne i velika. Većim izdvajanjem iz budžeta države za poljoprivredu došlo je do veće produktivnosti usled mogućnosti poljoprivrednih subjekata da zbog većih subvencija lakše dođu do efikasnije mehanizacije i opreme i nabavke kvalitetnijih obrtnih sredstava što će kasnije uticati na prinos. Većim prinosom poljoprivredni proizvođači će imati mogućnost da formiraju povoljniju cenu proizvoda, s kojom će biti konkurentniji i samim tim će ukupni saldo spoljnotrgovinske poljoprivredne 
proizvodnje da raste. Ovaj metod korelacije je autorima pomogao da pokažu da je finanisiranje poljoprivrede iz budžeta od velike važnosti.

Vremenskim linearnim trendom $u$ radu je utvrđivano kretanje agrarnog budžeta iz koga se vidi da je trend izdvajanja iz budžeta za poljoprivredu rastao. Primenom vremenskog linearnog trenda do 2030.godine, dolazi se do podatka da, ako bi se rast agrarnog budžeta nastavio, to bi dovelo do pojave većih izdataka na rashodnoj strani republičkog budžeta. Rastom izdvajanja iz budžeta kao što smo videli na dijagramu i ostalih izvora finansiranja koje smo pomenuli, za ciljnu 2030. godinu i uz plansko i sistematsko trošenje sredstava, poljoprivreda Srbije bi doživela procvat. Modelom linearnog trenda:

$$
\hat{y}=3,93+0,07 x
$$

i izračunavanjem njegove vrednosti za 2030. godinu dobija se iznos od 60.300,26 miliona dinara (Slika 1).

\section{ZAKLJUČAK / CONCLUSION}

Svaki oblik finansiranja predstavlja bitan faktor razvoja poljoprivrede. Tranzicija i prethodne ekonomske krize ostavile i negativne posledice kako na sve delove društva, tako i na poljoprivredu. Iz tog razloga, zastarela mehanizacija i nedovoljni stepen produktivnosti, karakterišu nekonkurentnu poljoprivredu naše zemlje. Takvo stanje uslovljava proizvode sa većom cenom koštanja i nekonkurentnu robu na tržištu, što se posebno odnosi na ruralne krajeve i male proizvođače.

Metodom korelacije utvrđeno je da rastom budžeta Republike Srbije rastu i izdvajanja za poljoprivredu ali i izdvajanja za agrarni budžet, kao i subvencije za poljoprivredu. Kao prvo potrebno je promeniti udeo države u agraru. Veći podsticaji poljoprivredi kroz subvencije bi inicirali još veću poljoprivrednu proizvodnju. Takođe jaka agrarna banka može značajno doprineti održivosti poljoprivrede. To bi otvorilo mogućnosti za finansiranje poljoprivrede i plasiranje kapitala, kako domaćeg tako i inostranog, da sve agrarne subverncije idu preko nje. Pri tom bi banka mogla obezbediti posebne pogodnosti za poljoprivredne proizvođače, nalik onima koje imaju pojedine zemlje u svetu.

Poslovne banke u državi imaju veliki uticaj na finansiranje poljoprivrede, te je to uslovilo da subjektima odnosno činiocima poljoprivrednih aktivnosti ponude povoljne kredite, sa nižom kamatnom stopom za obrtna sredstva i nabavku osnovnih sredstava. Međutim, svi ovi plasmani koje nude banke su kartkoročni poljoprivredni krediti sa otplatom do godinu dana. Potrebno je da poslovne banke delom posluju u interesu poljoprivrednika, a da pri tom ne ugoržavaju svoj interes. Naročit pozitivan efekat bi bio sistem odobravanja dugoročnih poljoprivrednih kredita sa nižom kamatom, bez valutne klauzule, sa dužim grejs periodom što bi u mnogome pomoglo poljoprivrednim subjektima jer je u poljoprivredi zastupljen spor obrt kapitala.

I na kraju možemo da zaključimo da je za oporavak i napredak poljoprivrede potrebna dominantna uloga države i državnog budžeta kao finansijske institucije. Ali, takođe, smatramo da je dominantnom ulogom države uzrokovana i nerazvijenost finansijskih tržišta i finansijskih institucija koje bi omogućile veće aktiviranje tržišnih mehanizama i sistema finansiranja poljoprivrede.

\section{LITERATURA / REFERENCES}

[1] Burda, M., Viploš, Č. (2012). Makroekonomija: evropski udžbenik, prevod 5. izd., Beograd: Centar za izdavačku delatnost Ekonomskog fakulteta u Beogradu.

[2] Devetaković, S., Jovanović Gavrilović B., Rikalović G. (2019). Nacionalna ekonomija. Beograd: Centar za izdavačku delatnost Ekonomskog fakulteta u Beogradu.

[3] Dominic, E, Tamás, F.M., Gábor, J.S. (2021). On relationships between the Pearson and the distance correlation coefficients. Statistics \& Probability Letters, 169, 108960. doi.org/10.1016 /j.spl.2020.108960

[4] Đurić, K., Prodanović, R., Čavlin, M., LukačBulatović, M. (2020). Ekonomske performanse agroindustrije u AP Vojvodini. Oditor, 6(2), 7-19. doi.org/10.5937/Oditor2002007D

[5] Ilić, J., Mihajlović, M., Savić, G.A., Dumonjić, G.J. (2017). Ekonomski instrumenti zaštite životne sredine, Ecologica, 24(87), 555-560.

[6] Ignjatijević, S., Aničić, A., Vapa-Tankosić, J., Belokapić-Čavkunović, J. (2020). Utvrđivanje ekonomskih relacija privrednog rasta i zaštite životne sredine. Oditor, 6(1), 38-48. doi.org/10.5937/ Oditor2001036I

[7] Knežević, G., Pavlović, V., Stevanović, S. (2017). Izveštavanje o održivom razvoju - karakteristike, ograničenja i perspektiva u Republici Srbiji. Poslovna ekonomija, 11(1), 83-102. doi.org/10.5937/ poseko11-13032

[8] Mihajlović, M., Krstić, S., Rstić, M. (2016). Uloga menadžmenta preduzeća u održivom razvoju, Ecologica, 23(82), 355-359.

[9] Milosavljević, S., Pantelejić, Đ., Međedović, D. (2019). Primena i mogućnost unapređenja ekonomskih činilaca u realizaciji održivog razvoja. Održivi razvoj, 1(1), 7-16. doi.org/10.5937/Odr Raz1901007M 
[10] Mladenović, Z., Nojković, A. (2015). Primenjena analiza vremenskih serija. Beograd: Centar za izdavačku delatnost Ekonomskog fakulteta $u$ Beogradu.

[11] Pantić, N., Jovanović, B., Issa, H. R. (2019). Oporezivanje u funkciji održivog razvoja. Održivi razvoj, 1(2), 37-51. doi.org/10.5937/OdrRaz1902037P

[12] Sachs, J., Schmidt-Traub, G., Kroll, C., Lafortune, G., Fuller, G. (2019). Sustainable Development Report 2019.

[13] Veličković, J., Jovanović, S. (2021). Problemi i mogući pravci održivog ruralnog razvoja Repu- blike Srbije. Economics of Sustainable Development, 5(1), 33-46. doi.org/10.5937/ESD2101 033V

[14] Veselinović, B., Drobnjaković, M. (2014). Kvalitativna i kvantitativna analiza mikro i makro aspekta agrarnih finansija. Ekonomika poljoprivrede, 61(3), 771-787.

[15] Zakon o ministarstvima. Sl. glasnik RS, br. 44/14 i $14 / 15$.

[16] Živković, S., Veljković, M. (2020). Koncept i ciljevi upravljanja zaštitom životne sredine. Economics of Sustainable Development, 4(2), 37-47. doi.org/ 10.5937/ESD2002037Z

[17] www.stat.gov.rs. 